\title{
Caracterización microscópica de la dentina de dientes temporales.
}

\section{Microscopic characterization of the dentin of temporary teeth.}

\author{
Juan Carlos Martínez Macal,* Iván Olin Moreno*
}

\section{RESUMEN}

La dentina se compone de un mineral de fosfato de calcio identificado como dahllita, que se dispone en pequeños cristales de hidroxiapatita carbonatada con dimensiones de $36 \times 25 \times 4 \mathrm{~nm}$, y por una fase orgánica cuyo principal componente es el colágeno tipo 1 en $90 \%$, que se orienta en forma de malla. Esta conformación corresponde a los dientes permanentes. Dentro de las estructuras, encontramos túbulos dentinarios que miden, aproximadamente, entre $0.5-1 \mu \mathrm{m}$ de diámetro en la periferia y hasta 3-5 $\mu \mathrm{m}$ cerca de la pulpa. En el presente estudio, realizado en dentina de dientes temporales, el lumen de dichos túbulos es más grande cuando se encuentra cerca de la pulpa dental. Asimismo, se encontraron cambios elementales importantes de acuerdo con las diferentes profundidades en las que se observó, encontrando un aumento en el peso porcentual de carbono cuando se encuentra a mayor profundidad, lo que indica una composición orgánica mayor en la dentina pulpar. En estudios de dientes permanentes esta composición es disminuida y con mayor concentración en la dentina cercana a la unión amelodentinaria. En dentina de dientes temporales se encontraron diferencias en el recuento de túbulos dentinarios por $\mathrm{mm}^{2}$, comparado a la dentina de dientes permanentes, donde el número de túbulos no varía mucho.

Palabras clave: Dentina, dentinogénesis, túbulos dentinarios.

\section{ABSTRACT}

Dentin is composed of a calcium phosphate mineral identified as dahllite, which is arranged in small crystals of carbonated hydroxyapatite with dimensions of $36 \times 25 \times 4 \mathrm{~nm}$, and by an organic phase whose main component is type l collagen in $90 \%$, which is oriented in the form of a mesh. This conformation corresponds to permanent teeth. Within the structures, we find dentin tubules that measure approximately 0.5-1 $\mu \mathrm{m}$ in diameter at the periphery and up to 3-5 um near the pulp. In the present study, carried out in dentin of primary teeth, the lumen of these tubules is larger when it is close to the dental pulp. Likewise, important elemental changes were found according to the different depths in which it was observed, finding an increase in the percentage weight of carbon when it is at a greater depth, indicating a greater organic composition in the pulp dentin. In studies of permanent teeth, this composition is decreased and with a higher concentration in the dentin near the amelodentinal junction. In dentin of primary teeth, differences were found in the count of dentin tubules per $\mathrm{mm}^{2}$, compared to dentin of permanent teeth, where the number of tubules did not vary much.

Keywords: Dentin, dentinogenesis, dentin tubules.

\section{INTRODUCCIÓN}

E ntre los tejidos duros del humano, el hueso y la dentina son los más semejantes entre sí, ya que ambos crecen por aposición, la única diferencia es que la dentina es avascular.
La hidroxiapatita en los tejidos mineralizados reviste una gran importancia: es el cristal principal en huesos y dientes y les confiere su dureza característica. ${ }^{1}$

La dentina es el principal tejido en el diente, ya que comprende la mayor porción de éste. Es una estructura sólida, que rodea a la pulpa y la protege, así como los demás

\footnotetext{
* Cirujano dentista. Lomas de Sotelo, Ciudad de México.
}

Recibido: 20 de agosto de 2020. Aceptado: 18 de julio de 2021.

Citar como: Martínez MJC, Olin MI. Caracterización microscópica de la dentina de dientes temporales. Rev ADM. 2021; 78 (6): 314-331. https://dx.doi. org/10.35366/102973 
elementos que constituyen al diente. Las células que forman este elemento principal del diente son los odontoblastos, estas células son postmitóticas de origen mesenquimal dispuestas en forma de palizada en la periferia de la pulpa dental y responsables de la formación de la dentina. ${ }^{2}$

Además de los componentes celulares, la dentina está compuesta por una parte inorgánica y otra orgánica. El 70\% de la estructura del diente permanente es inorgánica, $20 \%$ orgánica y $10 \%$ agua. La primera consiste principalmente de cristales de hidroxiapatita, mientras que la segunda está constituida en $90 \%$ de colágeno tipo I.

En la actualidad, los pocos estudios que identifican los compuestos y las estructuras que contiene la dentina en dientes deciduos no son suficientes para dar un buen tratamiento de restauración.

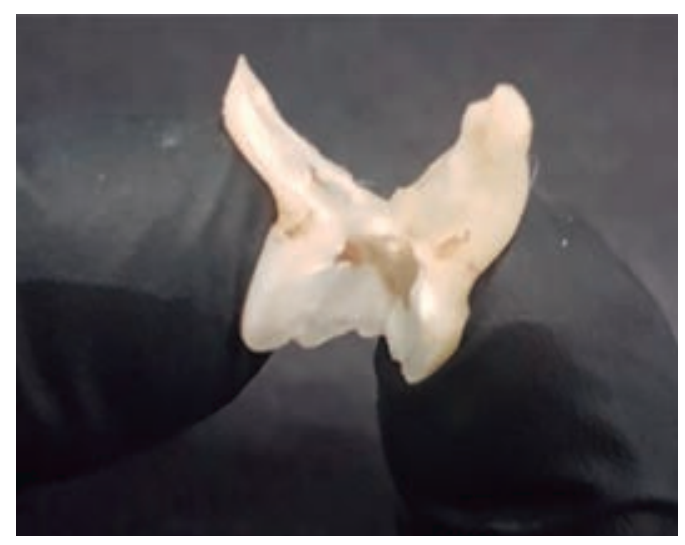

Figura 1: Obtención y sección del espécimen. Fuente: Directa.
El objetivo de este estudio es determinar las características morfológicas y de composición de la dentina mediante la aplicación del microscopio electrónico de barrido.

\section{MATERIAL Y MÉTODOS}

\section{Material}

Microscopio electrónico de barrido.

Tubos Eppendorf de $1.5 \mathrm{~mL}$.

Solución salina.

Ácido ortofosfórico al 37\%.

Insumos de laboratorio (portamuestras, cinta de carbón, adhesivo de carbón, recubrimiento de carbón), discos de diamante.

Agua tipo II.

\section{Métodos}

Se obtuvo un espécimen de un molar previa autorización y firma del consentimiento informado por parte del responsable del paciente, así como la entrega de un reconocimiento y obsequio al mismo paciente por aportar un diente a la investigación científica (Anexos 1 a 4).

Para la conservación del espécimen, fue sumergido en solución salina al $0.9 \%$ en un tubo Eppendorf de 1.5 $\mathrm{mL}$. Posteriormente, se realizó un corte sagital en el espécimen, obteniendo partes vestibular y lingual (Figura 1). Asimismo, se realizaron otros dos cortes en un plano sagital a la parte vestibular del espécimen, obteniendo tres muestras en tercios: vestibular, medio e interno (Figura 2).

Figura 2:

Sección del espécimen en tercio externo, medio e interno.

Fuente: Directa.
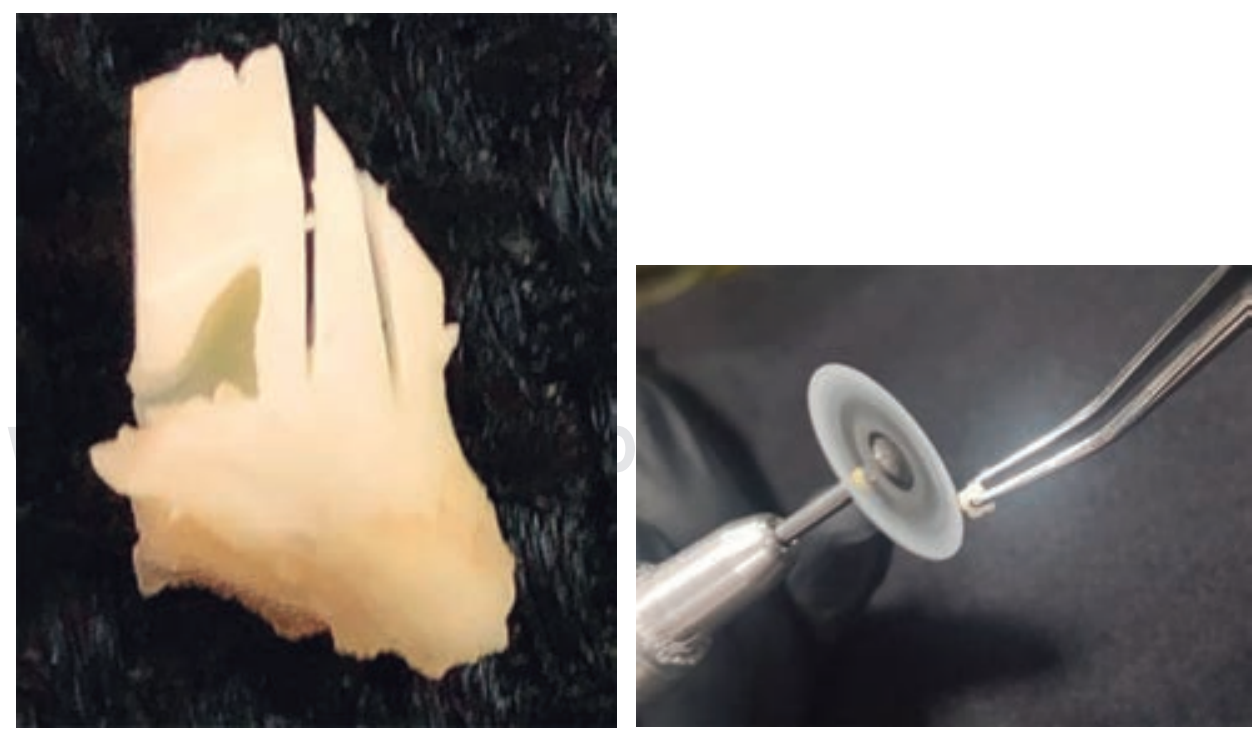

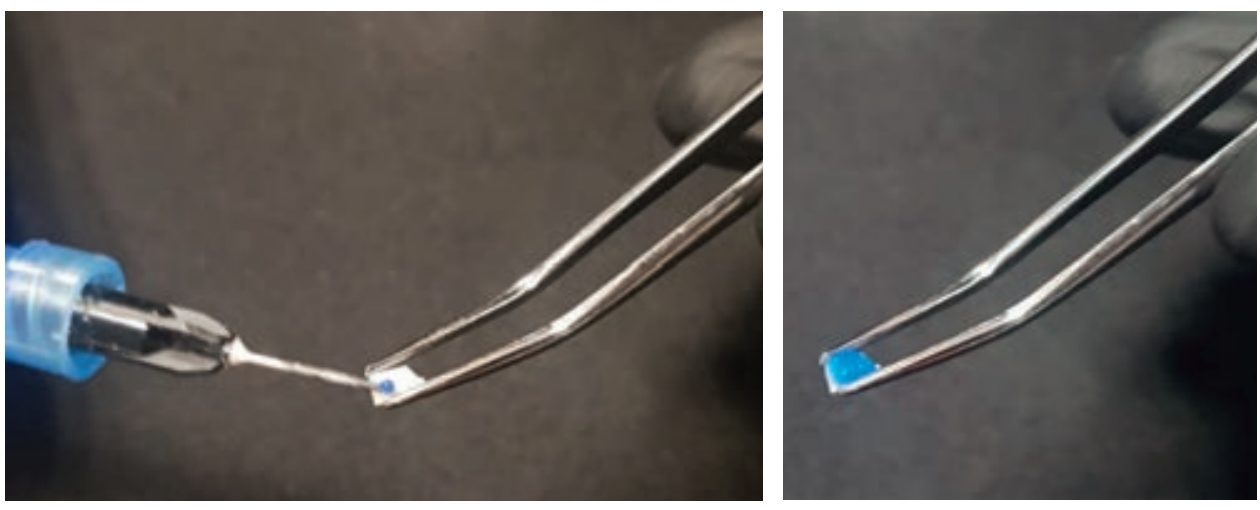

Figura 3:

Ataque con ácido ortofosfórico al $37 \%$ del tercio obtenido y grabado ácido durante ocho segundos.

Fuente: Directa.
Cada muestra fue grabada con ácido ortofosfórico al $37 \%$ durante ocho segundos (Figura 3).

Las muestras fueron lavadas con agua bidestilada durante un minuto, con el objetivo de eliminar el barrillo dentinario y obtener mayor calidad en las microfotografías del microscopio electrónico de barrido (Figura 4).

Cada tercio obtenido y preparado se colocó en un tubo Eppendorf de $1.5 \mathrm{~mL}$ con agua bidestilada para su conservación y remisión al Instituto de Física de la UNAM (IFUNAM) (Figura 5).

Una vez preparadas y conservadas en agua bidestilada durante 10 días, las muestras fueron observadas en el microscopio electrónico barrido de bajo vacío del IFUNAM a diferentes magnificaciones (Figura 6).

Las microfotografías obtenidas fueron analizadas en el software Image ${ }^{\circledR}$, herramienta que permitió realizar un conteo manual de 660 túbulos dentinarios (Figura 7).

Otra manera de cálculo de la densidad fue posible a través de la división del campo observado en 16 partes, previo establecimiento de la escala mediante la referencia indicada en cada microfotografía (Figuras 8 a 10).

Se realizó el recuento manual de los túbulos encontrados en 1/16 del área y el resultado se multiplicó por 16, obteniéndose un número de túbulos muy cercano al obtenido de manera manual en toda la extensión del área (Figura 10).

La observación de las muestras permitió obtener la densidad en los diferentes tercios, plasmando los datos en tablas de contingencia en hojas de cálculo de Excel.

Los datos de composición de la dentina fueron obtenidos mediante el microscopio electrónico de barrido (MEB) con detector de EDS (espectroscopia de rayos $\mathrm{X}$ de energía dispersa, por sus siglas en inglés). Este sistema identifica y cuantifica los rayos $\mathrm{X}$ característicos de los elementos químicos y genera información como espectros

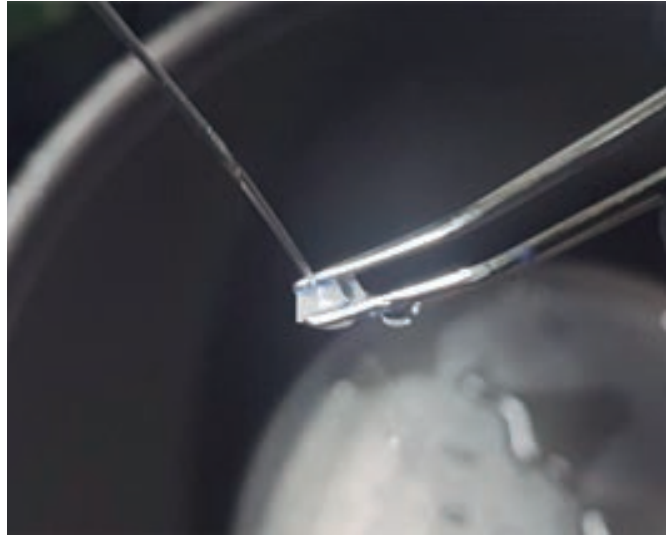

Figura 4: Lavado de la muestra con agua bidestilada. Fuente: Directa.

de intensidad contra energía de emisión en kiloelectrovoltios (keV), plasmándolos en una tabla e indicando el peso porcentual (Figura 11).

Se realizaron tres barridos por cada tercio y se obtuvo un promedio del peso porcentual por cada elemento que se encontró.

De esta forma, con el promedio del calcio y del fósforo, se determinó la relación estequiométrica (Tabla 1).

El lumen de los túbulos dentinarios se obtuvo a través de la herramienta «óvalo» del software Image ${ }^{\circledR}$, la cual permitió dibujar el contorno de 30 túbulos por cada tercio en sus diferentes microfotografías, y de esta manera obtener el perímetro (lumen) de los túbulos (Figura 12).

Los datos obtenidos se plasmaron en tablas de contingencia y se promediaron.

Por último, los datos obtenidos de densidad, composición elemental y lumen de cada tercio fueron comparados entre sí y graficados para observar las diferencias. 


\section{RESULTADOS}

\section{Medición de la densidad}

A continuación, se desglosan los resultados obtenidos de la densidad en los diferentes tercios, así como las comparaciones entre los mismos.

\section{Tercio externo}

A una magnificación promedio de $\times 2,007.33$ de tres microfotografías del tercio externo, se registraron 112 túbulos dentinarios en un área de $11.72 \mathrm{~mm}^{2}$ (Tabla 2).

Mientras tanto, a una magnificación de $\times 1,000$ de dos microfotografías del tercio externo, se registró un promedio de 433 túbulos en un área de $47.10 \mathrm{~mm}^{2}$ (Tabla 3).

A una magnificación de $\times 500$ de dos microfotografías del tercio externo, se registró un promedio de 1,632 túbulos dentinarios en un área de 188.23 mm² (Tabla 4).

\section{Tercio medio}

Respecto al tercio medio, en tres microfotografías a una magnificación promedio de $\times 2,000$, se registraron 181 túbulos dentinarios en un área de 11.84 $\mathrm{mm}^{2}$ (Tabla 5).

En tres microfotografías de muestras de este tercio, a una magnitud de $\times 1,000$ se registró un promedio de 858 túbulos dentinarios en un área de $47 \mathrm{~mm}^{2}$ (Tabla 6).

Mientras que en dos muestras observadas a una magnificación de $\times 500$, se registró un promedio de 2,960 túbulos dentinarios en un área de $188.67 \mathrm{~mm}^{2}$ (Tabla 7).

\section{Tercio interno}

Tratándose del tercio interno, en dos microfotografías a una magnificación de $\times 2,000$, se registró un promedio de 288 túbulos dentinarios en un área de $11.86 \mathrm{~mm}^{2}$ (Tabla 8).

En dos microfotografías a una magnificación de $\times 1,000$, se registró un promedio de 984 túbulos dentinarios en un área de $47.10 \mathrm{~mm}^{2}$ (Tabla 9).

Mientras tanto, en dos microfotografías a una magnificación de $\times 500$, se registró un promedio de 3,060 túbulos dentinarios en un área de $188.99 \mathrm{~mm}^{2}$ (Tabla 10).

Al realizar la comparación de ocho muestras de los diferentes tercios, de acuerdo al promedio de la magnificación $(\times 2,000)$ y área $\left(11.81 \mathrm{~mm}^{2}\right)$, se determina que existe mayor densidad en el tercio interno con 288 túbulos, resultando el externo el menos denso con 112 túbulos (Tabla 11).

Al realizar la comparación de siete muestras de los diferentes tercios, de acuerdo con la magnificación $(\times 1,000)$ y el promedio del área $\left(47.06 \mathrm{~mm}^{2}\right)$, se determina que existe mayor densidad en el tercio interno con 984 túbulos, resultando el externo el menos denso con 432 túbulos. Es notorio el acercamiento de la densidad del tercio medio al interno, con 859 túbulos dentinarios (Tabla 12).

Al realizar la comparación de seis muestras de los diferentes tercios, de acuerdo con la magnificación $(\times 500)$ y el promedio del área $\left(188.63 \mathrm{~mm}^{2}\right)$, se determina que existe mayor densidad en el tercio interno con 3,060 túbulos, resultando el externo el menos denso con 1,632 túbulos. Nótese la proximidad de la densidad de la dentina del tercio medio a la del interno, registrándose 2,960 túbulos (Tabla 13).
Figura 5:

Conservación de la muestra preparada en agua bidestilada para evitar contaminación. Muestra lista

para ser remitida al Instituto de Física de la UNAM (IFUNAM). Fuente: Directa.
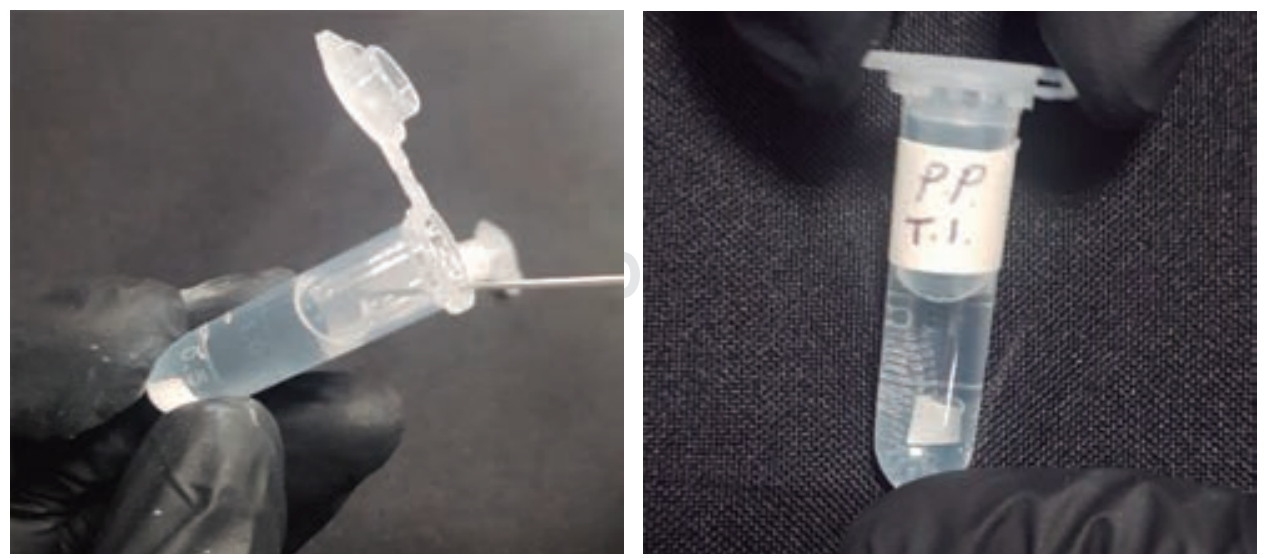


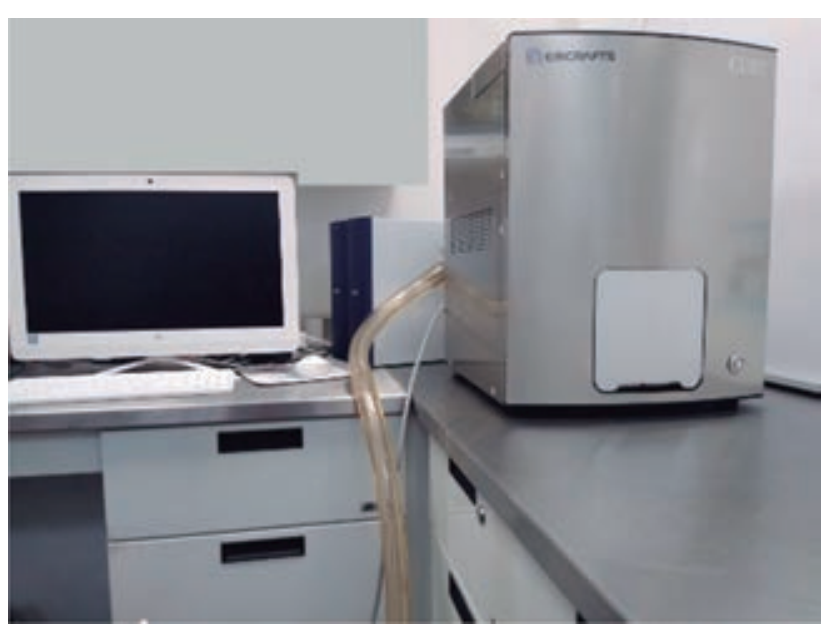

Figura 6: Microscopio electrónico de barrido de bajo vacío con detector espectroscopia de dispersión de energía de rayos X, marca EmCrafts ${ }^{\circledR}$, modelo Cube ${ }^{\circledR}$, resolución 5 nm, de origen coreano. Equipo utilizado para la obtención de las microfotografías de las muestras. Fuente: Directa.

\section{Resultados de la composición elemental}

El uso del MEB-EDS permitió el análisis microelemental de la composición de la dentina de primera dentición, habiéndose obtenido de tres barridos en diferentes áreas de cada tercio.

Los elementos que se detectaron en los espectros son oxígeno $(\mathrm{O})$, fósforo $(\mathrm{P})$, calcio $(\mathrm{Ca})$, magnesio $(\mathrm{Mg})$, silicio $(\mathrm{Si})$, sodio $(\mathrm{Na})$ y carbono $(\mathrm{C})$, mostrándose en peso porcentual $(\mathrm{Wt} \%)$ y estableciendo un promedio de cada elemento.

En el tercio externo se observa $59.26 \%$ de oxígeno, $14.10 \%$ de fósforo y un $25 \%$ de calcio, elementos que componen la hidroxiapatita. Se observan trazas de silicio, probablemente por el desprendimiento de partículas del disco con el que se realizó el corte del espécimen; trazas de sodio como posible consecuencia al medio de conservación inicial del espécimen en solución fisiológica al 0.9\%; así como trazas de magnesio, elemento que se encuentra en tejidos duros en desarrollo, como huesos y esmalte (Tabla 14).

En el tercio medio se observa $38.81 \%$ de carbono, elemento que demuestra la composición orgánica de la dentina, $38.16 \%$ de oxígeno, $14.15 \%$ de calcio y $8.25 \%$ de fósforo (Tabla 15).

En el tercio interno se observa $48.47 \%$ de carbono, elemento que demuestra la composición orgánica de la dentina, $32.19 \%$ de oxígeno, $12.53 \%$ de calcio y $6.48 \%$ de fósforo, así como trazas de silicio como posible partícula del disco empleado para el corte del espécimen (Tabla 16).

\section{Relación estequiométrica $\mathrm{Ca} / \mathrm{P}$}

Una vez obtenido el promedio de los elementos, se calculó la relación estequiométrica de calcio/fósforo $(\mathrm{Ca} / \mathrm{P})$, que determina el tipo de fosfato de calcio que se encuentra en cada uno de los tercios de la dentina.

En la Figura 13, en las barras correspondientes al tercio externo y medio, se observa las proporciones $\mathrm{Ca} / \mathrm{P}$ de 1.77 y 1.79 , respectivamente, valores aproximados a 1.67, que es la proporción de la hidroxiapatita pura o sintética; no obstante, la relación obtenida se trata de hidroxiapatita biológica.

Respecto a la proporción $\mathrm{Ca} / \mathrm{P}$ del tercio interno (1.93), el valor se encuentra aproximado a 2, correspondiente al fosfato tetracálcico sintético, utilizado como material de regeneración ósea guiada.

\section{Resultados de lumen}

Se determinó el lumen de los túbulos dentinarios mediante el empleo del programa de procesamiento de imagen digital Image ${ }^{\circledR}$, en las microfotografías de los tres diferentes tercios del espécimen a una magnificación de $\times 1,000$.

Asimismo, se estableció un promedio del lumen de los túbulos dentinarios de las muestras de cada

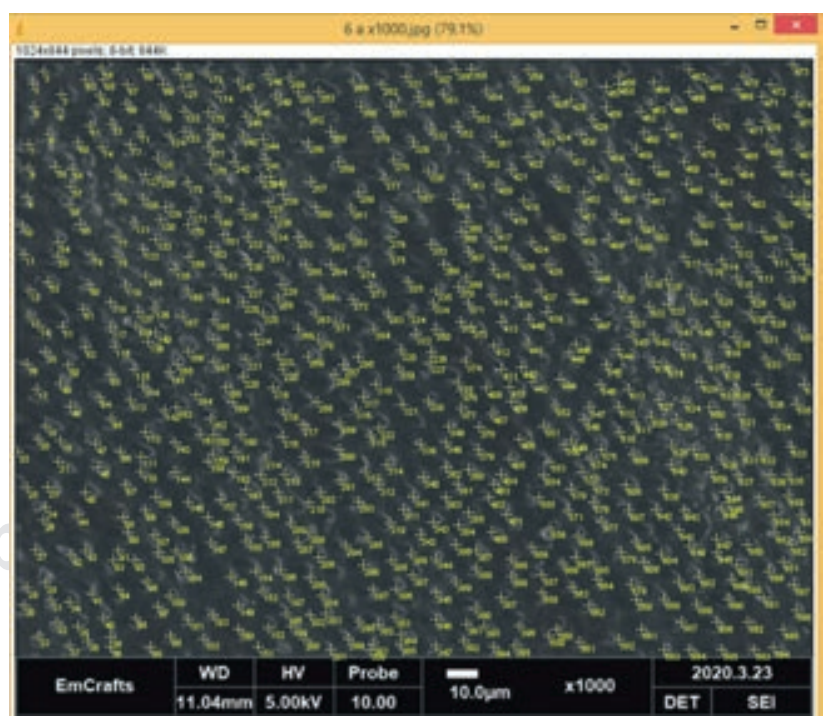

Figura 7: Conteo manual de 660 túbulos dentinarios con ImageJ ${ }^{\circledR}$ en microfotografía de tercio medio $\left(\times 1,000,47 \mathrm{~mm}^{2}\right)$. Fuente: Directa. 
tercio, así como el cálculo de la desviación estándar, el límite máximo y límite mínimo con la hoja de cálculo Microsoft Excel ${ }^{\circledR}$ del sistema operativo Windows $2007^{\circledR}$.

\section{Tercio externo}

En la Figura 14 se observan 30 túbulos dentinarios del tercio externo, registrando el túbulo más pequeño con $3.94 \mu \mathrm{m}$, hasta la identificación del túbulo más grande con $9.11 \mu \mathrm{m}$. El promedio es de $5.86 \mu \mathrm{m}$, así como una desviación estándar de $\pm 1.26 \mu \mathrm{m}$, obteniéndose un límite máximo de $7.13 \mu \mathrm{m}$ y un límite mínimo de $4.60 \mu \mathrm{m}$.

\section{Tercio medio}

En la Figura 15 se observan 30 túbulos dentinarios del tercio medio, registrando el túbulo más pequeño con $4.62 \mu \mathrm{m}$, hasta la identificación del túbulo más grande con $8.47 \mu \mathrm{m}$. El promedio es de $6.39 \mu \mathrm{m}$, así como una desviación estándar de $\pm 1.07 \mu \mathrm{m}$, obteniéndose un límite máximo de $7.46 \mu \mathrm{m}$ y un límite mínimo de $5.31 \mu \mathrm{m}$.

\section{Tercio interno}

En la Figura 16 se menciona el registro correspondiente a 30 túbulos dentinarios del tercio interno, registrando el

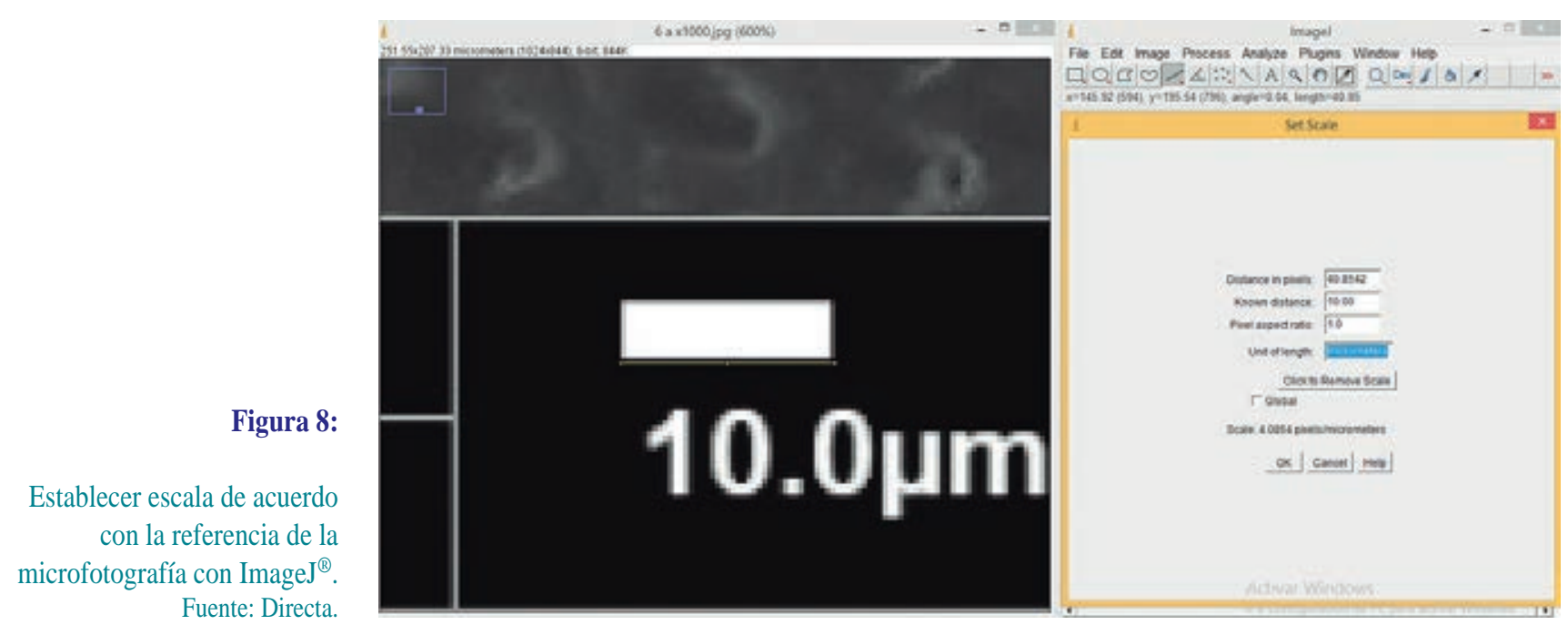

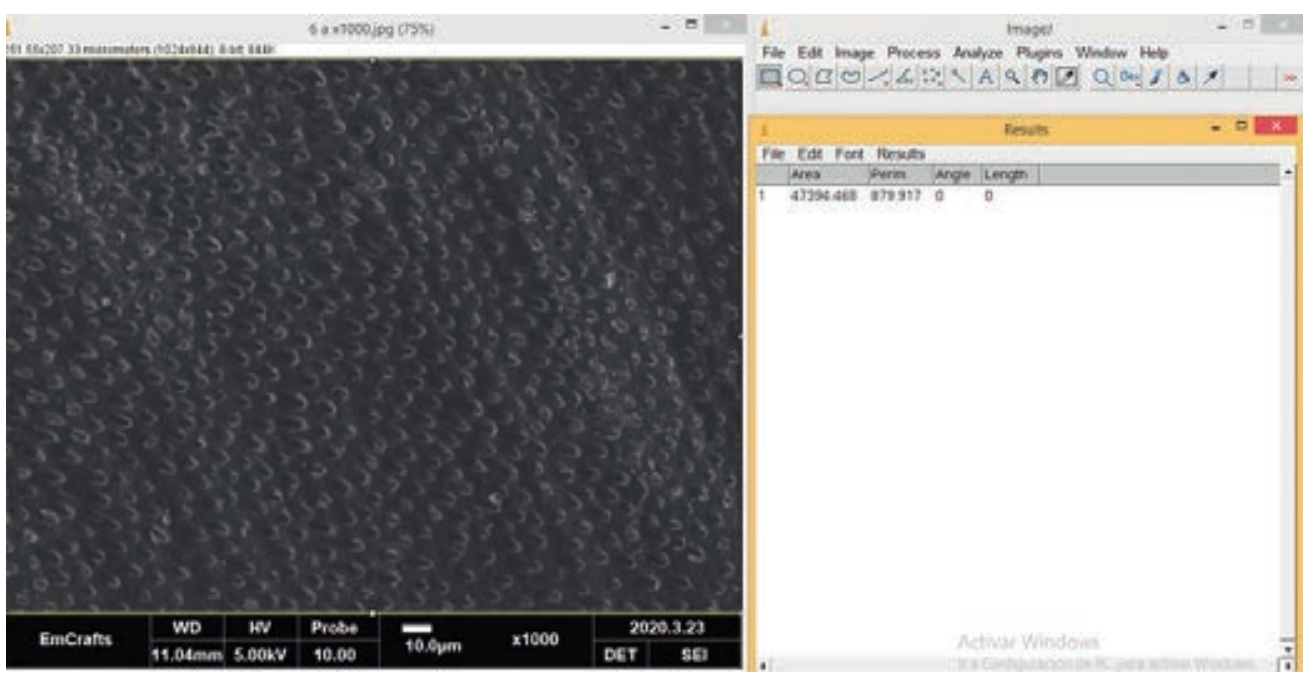

Figura 9:

Determinación del área de microfotografía con Image ${ }^{\circledR}$. Fuente: Directa. 
Figura 10:

Cálculo de 1/16 del área total de acuerdo con la referencia de la microfotografía con Image ${ }^{\circledR}$ y recuento del número de túbulos dentinarios en ella. Fuente: Directa.
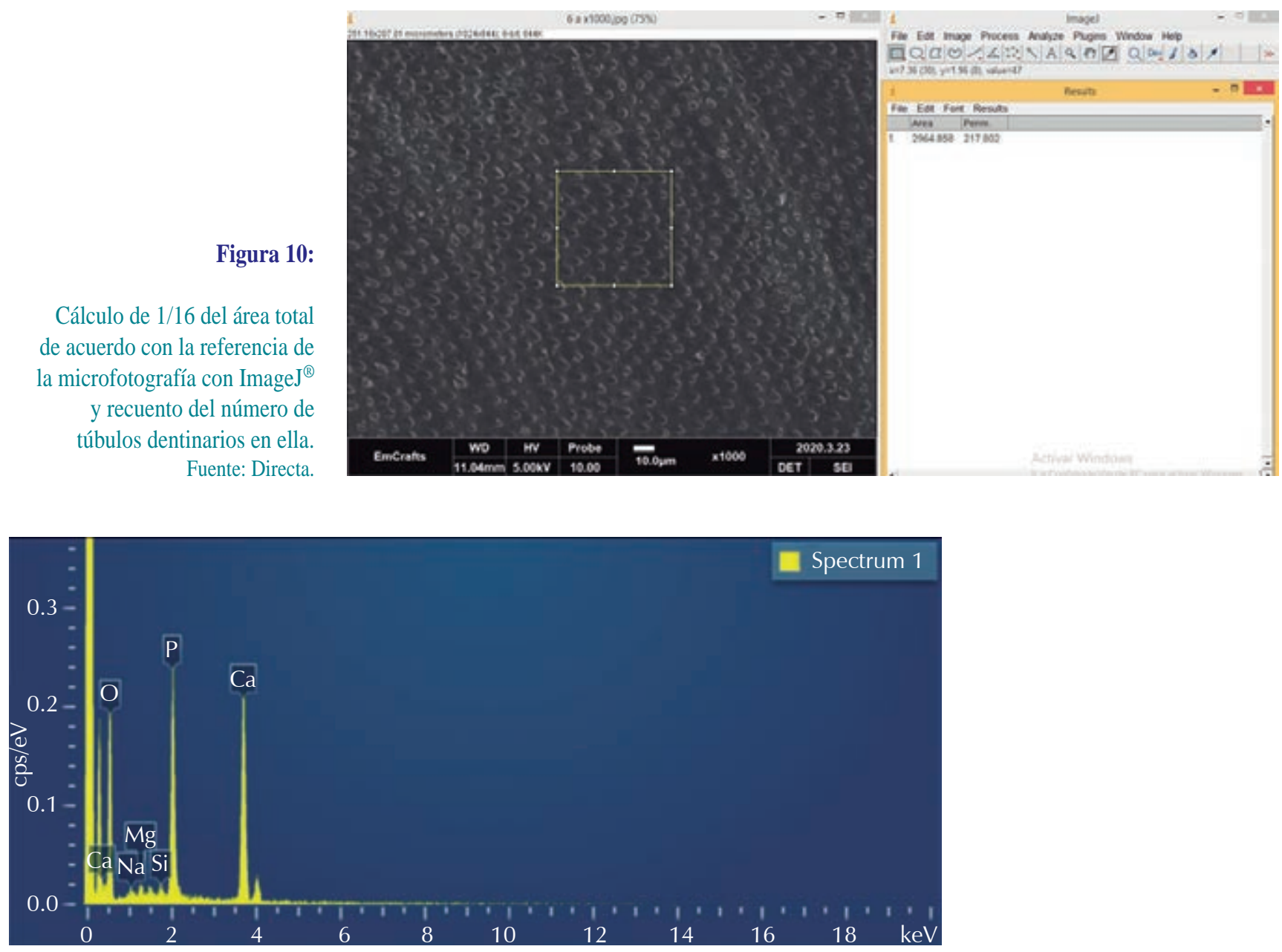

\begin{tabular}{ccccc} 
& \multicolumn{5}{c}{ Espectro 1 } & \\
Elemento & Tipo de línea & Peso \% & Peso sigma \% & Atómico \% \\
\hline O & K series & 58.71 & 0.96 & 75.89 \\
P & K series & 14.8 & 0.49 & 9.60 \\
Ca & K series & 24.95 & 0.70 & 12.88 \\
Mg & K series & 0.85 & 0.21 & 0.72 \\
Si & K series & 0.59 & 0.16 & 0.43 \\
Na & K series & 0.52 & 0.28 & 1.47 \\
Total & & 100.00 & & 100.00 \\
\hline
\end{tabular}

Figura 11:

Gráfica y tabla de datos arrojados por el sistema espectroscopia de rayos $\mathrm{X}$ de energía dispersa indicando elementos presentes en el barrido y pesos porcentuales. Fuente: Directa. túbulo más pequeño con $3.08 \mu \mathrm{m}$, hasta la identificación del túbulo más grande con $12.31 \mu \mathrm{m}$. El promedio es de $7.8 \mu \mathrm{m}$, así como una desviación estándar de $\pm 2.36 \mu \mathrm{m}$, obteniéndose un límite máximo de 10.16 m y un límite mínimo de $5.43 \mu \mathrm{m}$.
Se realizó la comparación del promedio del lumen de los túbulos dentinarios de los tres tercios del espécimen, registrando que el tercio interno es el que cuenta con túbulos con mayor lumen y los del tercio externo los que cuentan con menor lumen (Figura 17). 


\section{DISCUSIÓN}

El tamaño de la muestra inicial planeado para la elaboración del estudio constaba de cinco especímenes, sin embargo, fue necesario reducirlo a uno. Lo anterior, con motivo de una pandemia surgida durante el periodo en el que se desarrolló, viéndose limitado el tiempo de uso del MEB-EDS, así como del personal capacitado para su operación, en virtud de que todos los esfuerzos en investigación se avocaron a sortear citada emergencia sanitaria en el país. Por tal motivo, es recomendable llevar a cabo la presente investigación con mayor número de especímenes.

En la estructura de la dentina se pueden distinguir dos componentes básicos: la matriz mineralizada y los túbulos dentinarios que la atraviesan en todo su espesor y que alojan a los procesos odontoblásticos. ${ }^{3}$ Lo mismo ocurre en la dentina de dientes deciduos, sin embargo, existen diferencias en la densidad y en el lumen de los túbulos dentinarios.

Lainović T y colaboradores, ${ }^{4}$ en 2020, determinaron que es esencial caracterizar las propiedades mecánicas de los dientes para predecir y comprender el comportamiento de la caries dental, así como para diseñar procedimientos dentales restauradores e investigar sus problemas al someterse a desgaste. En el presente estudio se pudo observar cambios en la estructura de la dentina en diferentes profundidades, desde el número de túbulos dentinarios y la densidad, así como la composición elemental.

Cedillo J y Cedillo J ${ }^{5}$ en 2013 enunciaron que las propiedades de la dentina son determinantes en casi

Tabla 1: Conjunción de pesos porcentuales de los tres barridos del tercio externo y relación estequiométrica Ca/P.

\begin{tabular}{|c|c|c|c|c|c|}
\hline \multirow[b]{2}{*}{ Elemento/Wt \% } & \multicolumn{3}{|c|}{ Barridos } & \multirow[b]{2}{*}{$\mathrm{N}$} & \\
\hline & 1 & 2 & 3 & & \\
\hline 0 & 58.71 & 60.22 & 58.86 & 59.26 & \\
\hline$P$ & 14.38 & 13.97 & 13.94 & 14.10 & \\
\hline $\mathrm{Ca}$ & 24.95 & 25.02 & 25.08 & 25.02 & Estequiometría \\
\hline $\mathrm{Mg}$ & 0.85 & 0.00 & 1.14 & 0.66 & 1.774651218 \\
\hline $\mathrm{Si}$ & 0.59 & 0.00 & 0.00 & 0.20 & \\
\hline $\mathrm{Na}$ & 0.52 & 0.79 & 0.99 & 0.77 & \\
\hline
\end{tabular}

Fuente: Directa.

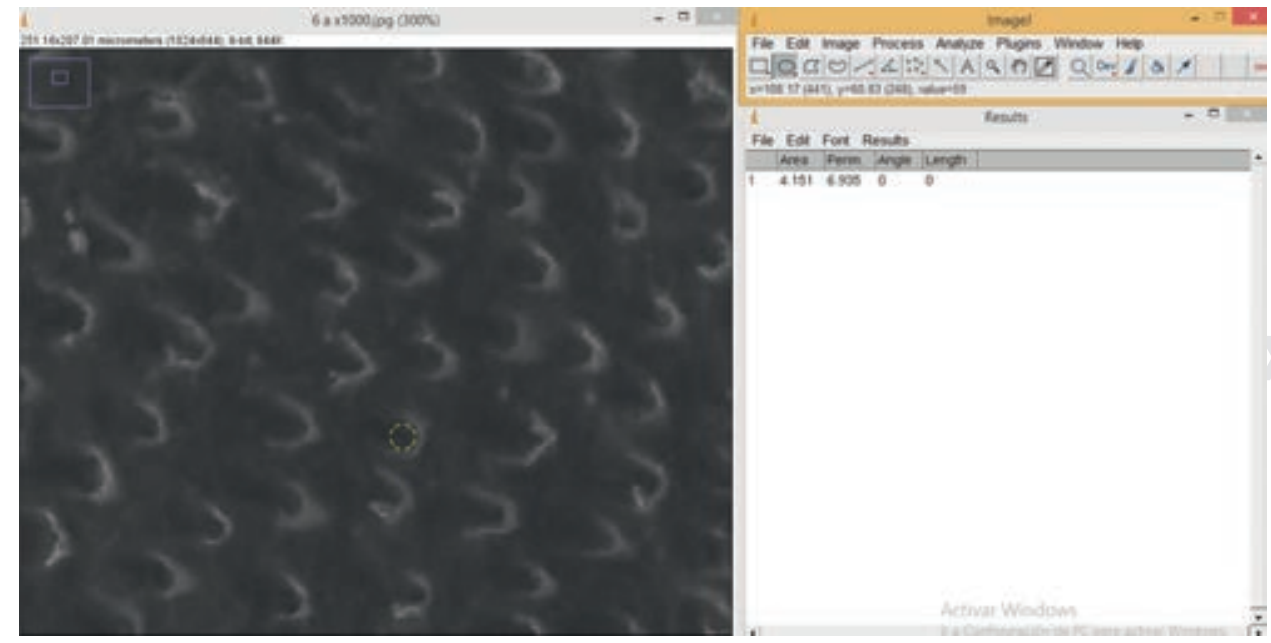

Figura 12:

Cálculo del lumen de los túbulos dentinarios de acuerdo con la referencia de la microfotografía con Image ${ }^{\circledR}$. Fuente: Directa. 
Tabla 2: Densidad de túbulos dentinarios en tercio externo de dientes de primera dentición.

\begin{tabular}{cccc} 
Muestra & Túbulos & Área $\left(\mathrm{mm}^{2}\right)$ & $\times$ \\
\hline 1 & 96 & 11.66 & 2,011 \\
2 & 96 & 11.95 & 2,011 \\
3 & 144 & 11.56 & 2,000 \\
Promedio & 112 & 11.72 & $2,007.33$ \\
\hline
\end{tabular}

Fuente: Directa.

\begin{tabular}{cccc}
\multicolumn{4}{|c}{ Tabla 3: Densidad de túbulos dentinarios en tercio externo } \\
de dientes de primera dentición.
\end{tabular}

Fuente: Directa.

\begin{tabular}{cccc}
\multicolumn{4}{c}{ Tabla 4: Densidad de túbulos dentinarios } \\
en tercio externo de dientes de primera dentición. \\
\hline Muestra & Túbulos & Área $\left(\mathrm{mm}^{2}\right)$ & $\times$ \\
\hline 6 & 1,712 & 188.23 & 500 \\
7 & 1,552 & 188.23 & 500 \\
Promedio & 1,632 & 188.23 & 500 \\
\hline
\end{tabular}

Fuente: Directa.

todos los procedimientos de odontología restauradora. Es un criterio para considerar en dientes deciduos y se propone que, con base en los resultados que se obtengan en futuros estudios con mayor número de muestras, se trace una línea de investigación que determine los mejores materiales para restaurar dientes deciduos o, de ser necesario, se desarrollen.

El grabado ácido aplicado en las muestras de la presente investigación se realizó en ocho segundos, a diferencia del estudio realizado por Berrios $\mathrm{M}^{6}$ en
2009, en el que se determinó que la variación del tiempo de aplicación del ácido ortofosfórico al 37\% (5 y 15 s) no produce diferencias significativas en el diámetro de los túbulos dentinarios abiertos. Cabe destacar que el estudio elaborado en 2009 se llevó a cabo en órganos dentales permanentes, por lo que se propone realizar investigaciones que implementen diferentes tiempos de grabado ácido en órganos dentales deciduos.

Tabla 5: Densidad de túbulos dentinarios en tercio medio de dientes de primera dentición.

\begin{tabular}{cccc} 
Muestra & Túbulos & Área $\left(\mathrm{mm}^{2}\right)$ & $\times$ \\
\hline 1 & 192 & 11.85 & 2,014 \\
2 & 192 & 11.85 & 2,000 \\
3 & 160 & 11.83 & 1987 \\
Promedio & 181 & 11.84 & $2,000.33$ \\
\hline Fuente: Directa. & & & \\
\end{tabular}

\section{Tabla 6: Densidad de túbulos dentinarios en tercio medio de dientes de primera dentición.}

\begin{tabular}{cccc} 
Muestra & Túbulos & Área $\left(\mathrm{mm}^{2}\right)$ & $\times$ \\
\hline 4 & 960 & 47 & 1,000 \\
5 & 960 & 47 & 1,000 \\
6 & 656 & 47 & 1,000 \\
Promedio & 858 & 47 & 1,000 \\
\hline
\end{tabular}

Fuente: Directa.

Tabla 7: Densidad de túbulos dentinarios en tercio medio
de dientes de primera dentición.

Fuente: Directa. 


\begin{tabular}{cccc}
\multicolumn{4}{c}{ Tabla 8: Densidad de túbulos dentinarios en tercio interno } \\
de dientes de primera dentición.
\end{tabular}

Fuente: Directa.

Tabla 9: Densidad de túbulos dentinarios

en tercio interno de dientes de primera dentición.

\begin{tabular}{crcc} 
Muestra & Túbulos & Área $\left(\mathrm{mm}^{2}\right)$ & $\times$ \\
\hline 3 & 1,008 & 47.00 & 1,000 \\
4 & 960 & 47.20 & 1,000 \\
Promedio & 984 & 47.10 & 1,000 \\
\hline
\end{tabular}

Fuente: Directa.

Tabla 10: Densidad de túbulos dentinarios en tercio interno
de dientes de primera dentición.

Fuente: Directa.

El estudio realizado por Abia y colegas, ${ }^{7}$ tuvo como hallazgo que el contenido mineral del esmalte y la dentina en los dientes primarios no se ven afectados por el consumo de agua desalinizada. Con esto puede decirse que la estructura de los componentes de dientes deciduos desarrollados en un inicio es la misma en todo momento en dientes sanos. Sin embargo, en el estudio realizado por Lezcano $M$ y su equipo ${ }^{8}$ se observaron cambios o alteraciones experimentados por los tejidos duros de los dientes caducifolios durante la transición, entre los cuales se determina que la dentina, que es un tejido que responde a estímulos, mostró la formación de dentina esclerótica y zonas muertas, dependiendo de la ubicación. Esto significaría una posible variable en la obtención de resultados de composición al momento de realizar el estudio en mayor número de muestras. Se recomienda para próximas investigaciones de este tipo considerar el lugar de origen del paciente, así como el motivo de la pérdida del órgano dentario.

\begin{tabular}{|c|c|c|}
\hline Tercio & Densidad (túbulos $/ \mathrm{mm}^{2}$ ) & Área \\
\hline Externo & 112 & 11.72 \\
\hline Medio & 181 & 11.84 \\
\hline Interno & 288 & 11.86 \\
\hline Promedio & & 11.81 \\
\hline
\end{tabular}

\begin{tabular}{|c|c|c|}
\hline Tercio & Densidad (túbulos/mm²) & Área $\left(\mathrm{mm}^{2}\right)$ \\
\hline Externo & 433 & 47.10 \\
\hline Medio & 858 & 47.00 \\
\hline Interno & 984 & 47.10 \\
\hline Promedio & & 47.06 \\
\hline
\end{tabular}

Fuente: Directa.

\begin{tabular}{|c|c|c|}
\hline Tercio & Densidad (túbulos/mm²) & Área \\
\hline Externo & 1,632 & 188.23 \\
\hline Medio & 2,960 & 188.67 \\
\hline Interno & 3,060 & 188.99 \\
\hline Promedio & & 188.63 \\
\hline
\end{tabular}

Fuente: Directa. 
Así como lo describieron Goldberg M y colaboradores, ${ }^{9}$ la dentina es un rompecabezas de diferentes tipos de dentina, que refleja diferentes funciones y tiene sus propias especificidades. Esta investigación demuestra que en los dientes temporales se observan diferencias a distintas profundidades, contemplando que la dentina que está cercana a la cámara pulpar contiene un mayor número de túbulos dentinarios, volviéndola más densa, caso contrario a la dentina más próxima a la unión amelodentinaria.

Este fenómeno es atribuible a la atrición ocasionada por el bruxismo natural que presenta el paciente para estimular el recambio dental. Se puede determinar que es un punto importante a considerar al momento de realizar preparaciones de cavidades para restaurar este tipo de órganos dentales. Ello determinará el éxito del tratamiento, así como el riesgo predecible de que fracase.

Además, otro factor al que se atribuye una disminución de la luz de túbulos de dentina superficial es la caries dental, causando afecciones de las diversas estructuras del diente, especialmente en la dentición infantil, siendo necesario un tratamiento restaurador para recuperar su función y estética. ${ }^{10}$

M Navarro en 2006, ${ }^{11}$ afirmó que los túbulos de dientes permanentes se extienden desde la cámara pulpar hasta la unión amelodentinaria, y que varían en número y pueden representar desde $1 \%$ del área total de la superficie de la dentina junto a la unión amelodentinaria y aumentar en dirección a la pulpa hasta $22 \%$ del área total de superficie de la dentina.

\section{Tabla 14: Análisis microelemental del tercio externo en peso porcentual y su promedio.}

\begin{tabular}{ccccc} 
& \multicolumn{3}{c}{ Barridos } & \\
\cline { 2 - 4 } Elemento/Wt $\%$ & 1 & 2 & 3 & $\mathrm{n}$ \\
\hline $\mathrm{O}$ & 58.71 & 60.22 & 58.86 & 13.26 \\
$\mathrm{P}$ & 14.38 & 13.97 & 13.94 & 25.02 \\
$\mathrm{Ca}$ & 24.95 & 25.02 & 1.14 & 0.66 \\
$\mathrm{Mg}$ & 0.85 & 0.00 & 0.00 & 0.20 \\
$\mathrm{Si}$ & 0.59 & 0.00 & 0.99 & 0.77 \\
$\mathrm{Na}$ & 0.52 & 0.79 & & \\
\hline
\end{tabular}

Fuente: Directa.

Tabla 15: Análisis microelemental del tercio medio en peso porcentual y su promedio.

\begin{tabular}{|c|c|c|c|c|}
\hline \multirow[b]{2}{*}{ Element/Wt \% } & \multicolumn{3}{|c|}{ Barridos } & \multirow[b]{2}{*}{ Promedio } \\
\hline & 1 & 2 & 3 & \\
\hline 0 & 37.32 & 38.49 & 38.67 & 38.16 \\
\hline $\mathrm{P}$ & 8.30 & 8.40 & 8.05 & 8.25 \\
\hline $\mathrm{Ca}$ & 14.28 & 15.01 & 15.04 & 14.78 \\
\hline $\mathrm{Mg}$ & 0.00 & 0.00 & 0.00 & 0.00 \\
\hline $\mathrm{Si}$ & 0.00 & 0.00 & 0.00 & 0.00 \\
\hline $\mathrm{Na}$ & 0.00 & 0.00 & 0.00 & 0.00 \\
\hline $\mathrm{C}$ & 40.09 & 38.10 & 38.24 & 38.81 \\
\hline
\end{tabular}

Fuente: Directa. 
Tabla 16: Análisis microelemental del tercio interno en peso porcentual y su promedio.

\begin{tabular}{|c|c|c|c|c|}
\hline \multirow[b]{2}{*}{ Element/Wt \% } & \multicolumn{3}{|c|}{ Barridos } & \multirow[b]{2}{*}{ Promedio } \\
\hline & 1 & 2 & 3 & \\
\hline $\mathrm{O}$ & 33.33 & 31.01 & 32.24 & 32.19 \\
\hline $\mathrm{P}$ & 7.82 & 5.91 & 5.72 & 6.48 \\
\hline $\mathrm{Ca}$ & 15.04 & 11.48 & 11.08 & 12.53 \\
\hline $\mathrm{Mg}$ & 0.00 & 0.00 & 0.00 & 0.00 \\
\hline $\mathrm{Si}$ & 0.00 & 0.45 & 0.50 & 0.32 \\
\hline $\mathrm{Na}$ & 0.00 & 0.00 & 0.00 & 0.00 \\
\hline $\mathrm{C}$ & 43.81 & 51.16 & 50.45 & 48.47 \\
\hline
\end{tabular}

Fuente: Directa.

En dentina de órganos dentales temporales ocurre un fenómeno parecido. Esta organización determina un comportamiento anisotrópico de la dentina, es decir, las propiedades del substrato difieren según la dirección considerada.

R Gisela y su grupo, ${ }^{12}$ en 2013, determinaron que la materia inorgánica de la dentina de dientes permanentes consiste principalmente de cristales de hidroxiapatita y en menor proporción de fosfatos amorfos y carbonatos. Con los resultados obtenidos en esta investigación, se observa una composición semejante en dientes deciduos. Mediante la relación estequiométrica de calcio y fosfato, es notable la presencia de hidroxiapatita biológica, observándose un aumento de esta relación cuanto más cercanos se encuentren a la cámara pulpar.

La dentina de los dientes deciduos es ligeramente menos dura que la de los dientes permanentes y menos gruesa. Esto se debe a la relación con la cámara pulpar de cada diente; sus túbulos dentinarios son más estrechos cerca del esmalte. ${ }^{8}$ Los resultados obtenidos en ese año son similares a los que se obtuvieron en el presente estudio, puesto que la forma que se presenta en los túbulos dentinarios es cónica, ya que se encontró que cerca de la pulpa estos son de un lumen más grande que los que se encuentran cerca del esmalte.

Argüello ${ }^{13}$ en el año 2012 mencionó la conformación de la dentina y el esmalte, dándole un enfoque a las restauraciones, permitiendo conocer las características del tamaño de los lúmenes e indicando que, para que se obtenga un tratamiento efectivo, éste debe constar de materiales que sean hidrófobos, esto permitiría una mejor adhesión a la dentina. A la fecha no hay estudios

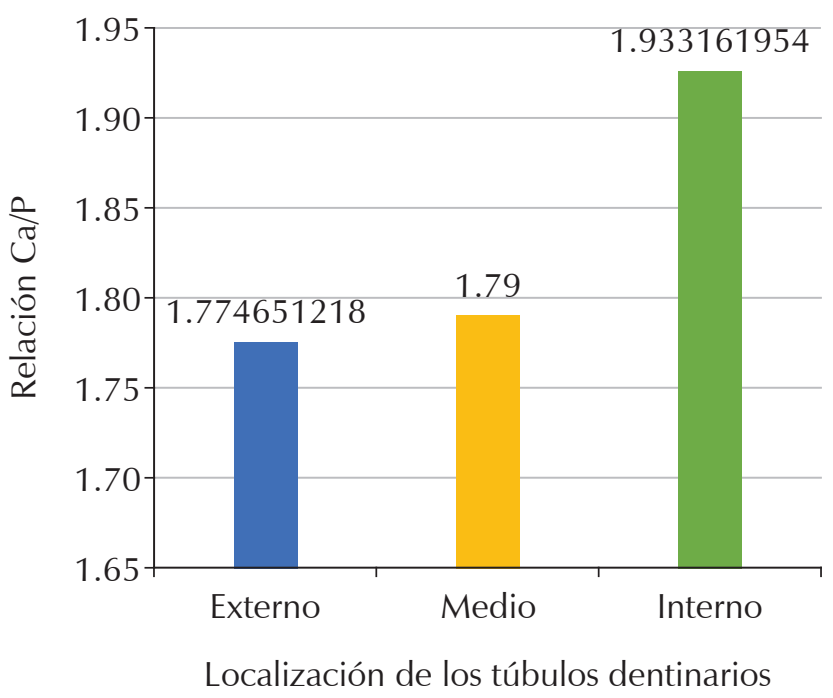

Figura 13: Relación estequiométrica $\mathrm{Ca} / \mathrm{P}$ en las diferentes zonas de la dentina de dientes de primera dentición.

de materiales que sean de primera elección para la dentina primaria.

La principal causa de tratamientos de restauración en niños es la caries, ya que afecta desde la estructura más superficial del diente hasta la más profunda. Es por ello que los odontólogos realizan trabajos de restauración, la mayoría con composites. ${ }^{14}$ Estaki $^{15}$ en 2018 observó que la mayor parte de la adhesión de los materiales de restauración operatoria se da en la unión amelocementaria, considerando que se dé un buen tiempo de grabado ácido. En dientes permanentes este 
tipo de tratamiento es efectivo, pues el lumen de sus túbulos es más amplio en esta parte, permitiendo una mejor retención de este tipo de materiales posterior al grabado ácido, mientras que en la dentina de dientes deciduos los lúmenes son más estrechos y los fracasos de adhesión son más factibles.

Sabel, en 2020, ${ }^{16}$ en su estudio Microanálisis de rayos $X$ de dentina en dientes primarios diagnosticados con dentinogénesis imperfecta encontró que la dentina expuesta es más compacta y que no tiene organización en sus túbulos dentinarios, refiere que una de las causas por lo que sucede es la sequedad de los túbulos, lo cual impide la correcta adhesión de materiales. A comparación de este estudio se encontró que los túbulos dentinarios se encuentran organizados en forma de panal. Como ya se mencionó antes, para que se dé un buen tratamiento de restauración y no se dañen las estructuras dentales, se deben elegir materiales hidrófobos, pues estos podrían tener mayor adhesión en la dentina decidua.

\section{CONCLUSIONES}

La densidad de la dentina en dientes temporales depende de la cercanía a la cámara pulpar, observándose que a mayor cercanía, mayor número de túbulos dentinarios en un área determinada, mientras que a mayor lejanía, menor número de túbulos; en comparación con investigaciones anteriores en dientes permanentes, donde los túbulos dentinarios disminuyen en número cuanto más cercanos se encuentren a la cámara pulpar.

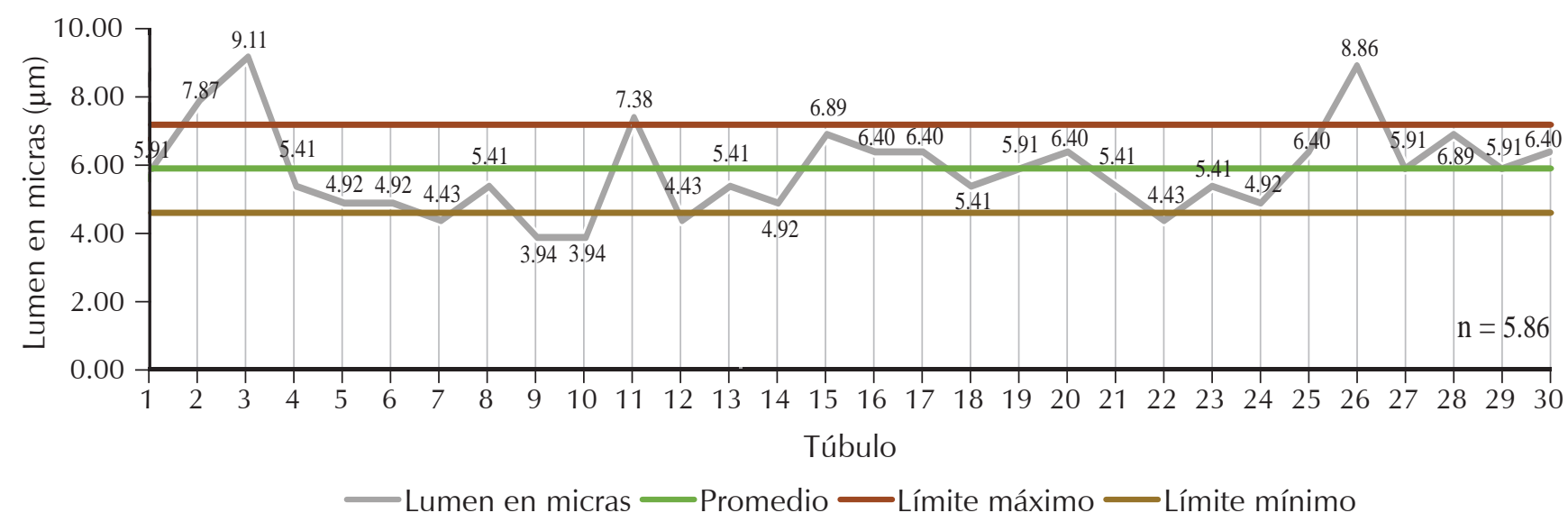

Figura 14: Desviación estándar del lumen de los túbulos dentinarios en el tercio externo. Fuente: Directa.

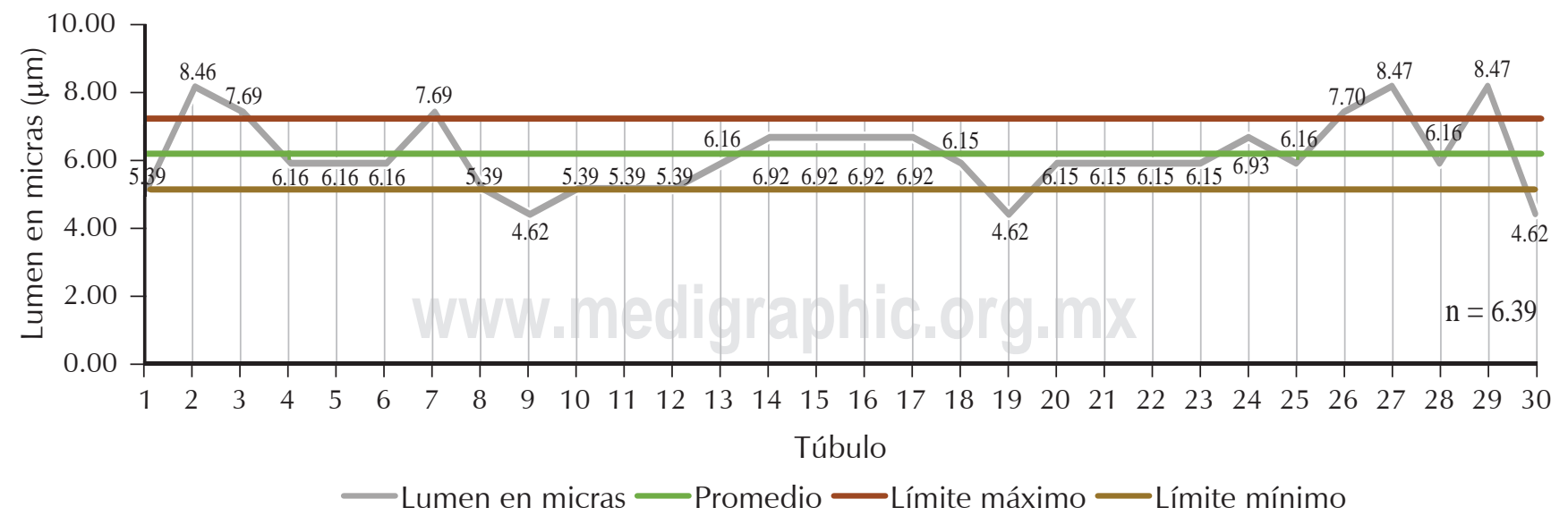

Figura 15: Desviación estándar del lumen de los túbulos dentinarios en el tercio medio. Fuente: Directa. 


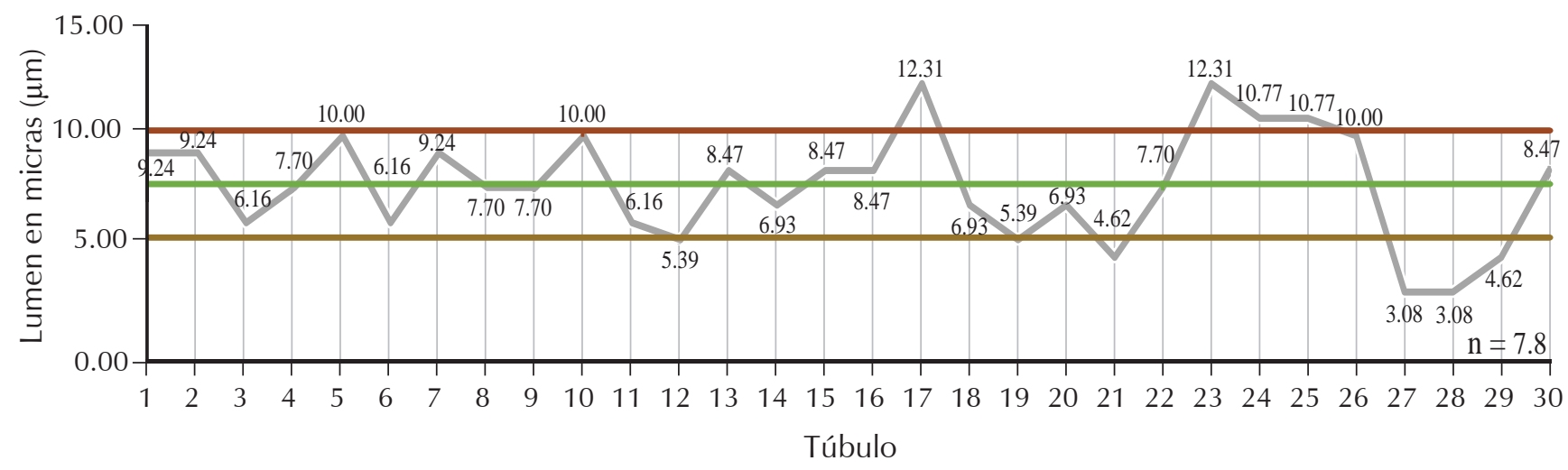

—Lumen en micras —Promedio —Límite máximo —Límite mínimo

Figura 16: Desviación estándar del lumen de los túbulos dentinarios en el tercio interno. Fuente: Directa

La composición elemental de la dentina de dientes deciduos manifiesta cambios importantes dependientes de la profundidad.

Existe un aumento en el peso porcentual de carbono cuando se encuentra a mayor profundidad, lo que se traduce a una mayor composición orgánica en la dentina cercana a dicha cámara pulpar. Contrario a la idea anterior, existe una disminución del peso porcentual de los elementos calcio y fósforo cuanto más cercanos se encuentren a multicitada cámara, lo que significa mayor composición inorgánica de la dentina cercana a la unión amelodentinaria.

En estudios previos en dientes permanentes, en la composición elemental se encontraron pequeñas cantidades de magnesio, a diferencia de la dentina decidua, donde únicamente se presentaron trazas de este elemento.

La relación estequiométrica de $\mathrm{Ca} / \mathrm{P}$ registra un aumento cuanto más cercano se encuentre a la cámara pulpar.

Se concluye que el promedio del lumen de los túbulos dentinarios de dientes temporales aumenta cuanto más cercanos se encuentran a la cámara pulpar y disminuye cuando éstos se encuentran más alejados.

Comparado con estudios anteriores, las diferencias anatómicas que existen entre los dientes permanentes y deciduos son considerables, dependientes de las profundidades a las que se observaron las muestras.

El conocimiento adquirido en esta investigación beneficia a los cirujanos dentistas y especialistas en odontopediatría, profundizando en las características de la dentina de dientes temporales.

Se concluye que el presente estudio beneficia al Instituto Armado, estribando en ser pionero en la investigación y aportación del conocimiento base de la dentina de dientes

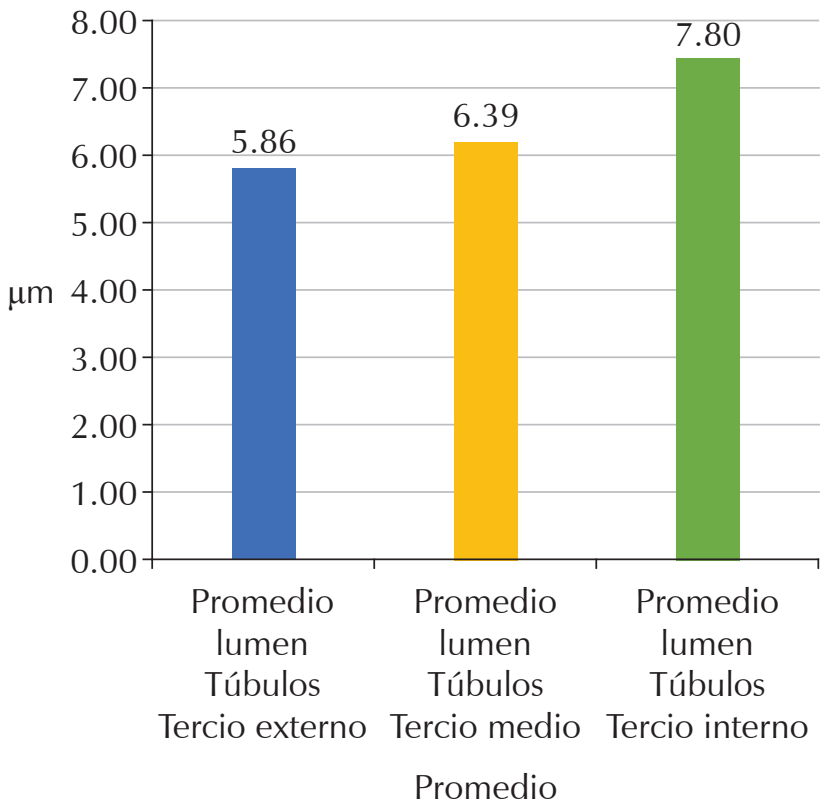

Figura 17: Diferencia del lumen promedio de los diferentes tercios de la dentina de dientes deciduos.

temporales, iniciando una línea de investigaciones futuras para determinar el mejor material de adhesión y/o el desarrollo de materiales adhesivos adecuados, que mejoren la calidad del servicio odontológico a los derechohabientes y a la población infantil mexicana en general.

\section{REFERENCIAS}

1. García-Garduño MV, Reyes-Gasga J. La hidroxiapatita, su importancia en los tejidos mineralizados y su aplicación biomédica. 
Tip Revista Especializada en Ciencias Químico-Biológicas [en linea]. 2006; 9 (2), 90-95. ISSN: 1405-888X. Disponible en: https://www. redalyc.org/articulo.oa?id $=43211937005$

2. Simanca VH. Fisiopatología de los odontoblastos: una revisión. Duazary. 2019; 16 (3): 87-103. Disponible en: https://doi. org/10.21676/2389783X.2971.

3. Diaz A, Villegas KM, Mandalunis PM. Revista de la facultad de odontología de Buenos Aires Argentina. Odontología FOUBA. 2018. Disponible en: http://odontologia.uba.ar/wp-content/ uploads/2019/02/Alteraciones-dentina.pdf

4. Lainović T, Margueritat J, Martinet Q, Dagany X, Blazic L, Pantelic D et al. Micromechanical imaging of dentin with Brillouin microscopy. Acta Biomater. 2020; 105: 214-222. Available in: https://doi. org/10.1016/j.actbio.2020.01.035

5. Cedillo VJJ, Cedillo FJE. Protocolo clínico actual para restauraciones profundas. Rev ADM. 2013; 70 (5): 263-275.

6. Berrios M, López JC. Caracterización de la dentina en sus diferentes etapas previas a la adhesión. Revista MeduLA. 2009; 1 (2): 2-5 Sitio Web: https://www.researchgate.net/publication/45161139_ Caracterizacion_de_la_dentina_en_sus_diferentes_etapas_ previas_a_la_adhesion

7. Abia-Arrieta B, Mautino Chang-Navarro L. et al. Interpretación radiográfica de enfermedades pulpares en dientes deciduos y permanentes. Trabajo de investigación, Odontopediatría II. 2008. Universidad Nacional Mayor de San Marcos, Facultad de Odontología, Lima Perú. pp-49. https://sisbib.unmsm.edu.pe/ bibvirtualdata/monografias/alumnos/mautino_cl.pdf

8. Lezcano MR, Solis AEP, Gili MA, Zamudio ME. Histomorfología de la atrición en dientes temporarios. Odontoestomatología. 2015; 17 (26): 4-11. Disponible en: http://www.scielo.edu.uy/scielo. php?script=sci_arttext\&pid=S1688-93392015000200002\&lng $=\mathrm{es} \& \mathrm{nrm}=$ iso \& $\operatorname{ting}=\mathrm{en}$

9. Goldberg M, Kulkarni AB, Young M, Boskey A. Dentin: structure, composition and mineralization. Front Biosci (Elite edition). 2011; 3: 711-735. Available in: https://doi.org/10.2741/e281.

10. González RS, Pedroso RL, Rivero VM, et al. Epidemiología de la caries dental en la población venezolana menor de 19 años.
Revista de Ciencias Médicas de la Habana. 2014; 20 (2): 208-218. Disponible en: http://revcmhabana.sld.cu/index.php/rcmh/article/ view/382/632

11. Navarro MA. Conceptos actuales sobre el complejo dentino pulpar. (Tesis doctoral). Universidad Central de Venezuela. Venezuela. 2005.

12. Ramos Sánchez G, Calvo Ramírez N, Fierro Medina R. Adhesión convencional en dentina, dificultades y avances en la técnica. Rev Fac Odontol Univ Antioq [Internet]. [cited 2021 Dec 16] 2015; 26 (2): 468-486.

13. Arguello OR, Guerrero IJ, Celis RL. Microfiltración in vitro de tres sistemas adhesivos con diferentes solventes. Rev Odont Mex. 2012; 16 (3): 188-192. [Recuperado en 10 de agosto de 2020] Disponible en: http://www.scielo.org.mx/scielo.php?script=sci arttext\&pid=S1870-199X2012000300006\&lng=es\&tlng=es

14. Estaki Z, Afshar H, Ghadimi S, Derakhshan S. Effect of Layering Technique on Push-Out Bond Strength of Composite Resin to Intracanal Dentin of Primary Anterior Teeth. J Dent (Tehran). 2018; 15 (5): 300-308.

15. Estaki Z, Afshar H, Ghadimi S, Derakhshan S. Efecto de la técnica de estratificación sobre la resistencia de la unión de la resina compuesta a la dentina intracanal de los dientes anteriores primarios. J Dent (Tehran). 2018; 15 (5): 300-308.

16. Sabel N, Norén JG, Robertson A, Cornell DH. X-ray microanalysis of dentine in primary teeth diagnosed Dentinogenesis Imperfecta type II. Eur Arch Paediatr Dent. 2020; 21 (4): 527-535.

Conflicto de intereses: Los autores declaran no tener conflicto de intereses.

Aspectos éticos: Ninguno.

Financiamiento: No se recibió ningún financiamiento.

Correspondencia:
Iván Olin Moreno
E-mail: ivolin93@gmail.com




\section{Anexos}

Anexo 1: Formato de carta de consentimiento válidamente informado para la donación y obtención de los especímenes.

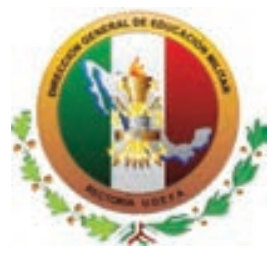

Yo de ma el día de

Nombre del donador
Universidad del Ejército y Fuerza Aérea

Escuela Militar de Odontología

Carta de Consentimiento Informado para la Donación de Órganos Dentarios

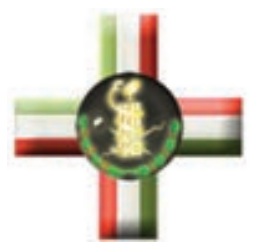

Firma

Declaración del Presentador de Servicio

He explicado al paciente o persona autorizada para otorgar el presente consentimiento, el uso que se hará (investigación) con la donación del órgano dentario. El/la padre*madre o tutor(a) del paciente donante ha comprendido la explicación y ha consentido la donación del (los) órgano

(s) dentario (s) en pleno uso de mis facultades, por mi propio derecho, * (s) dentario (s) 
Anexo 2: Formato 1 de certificado para el donante.

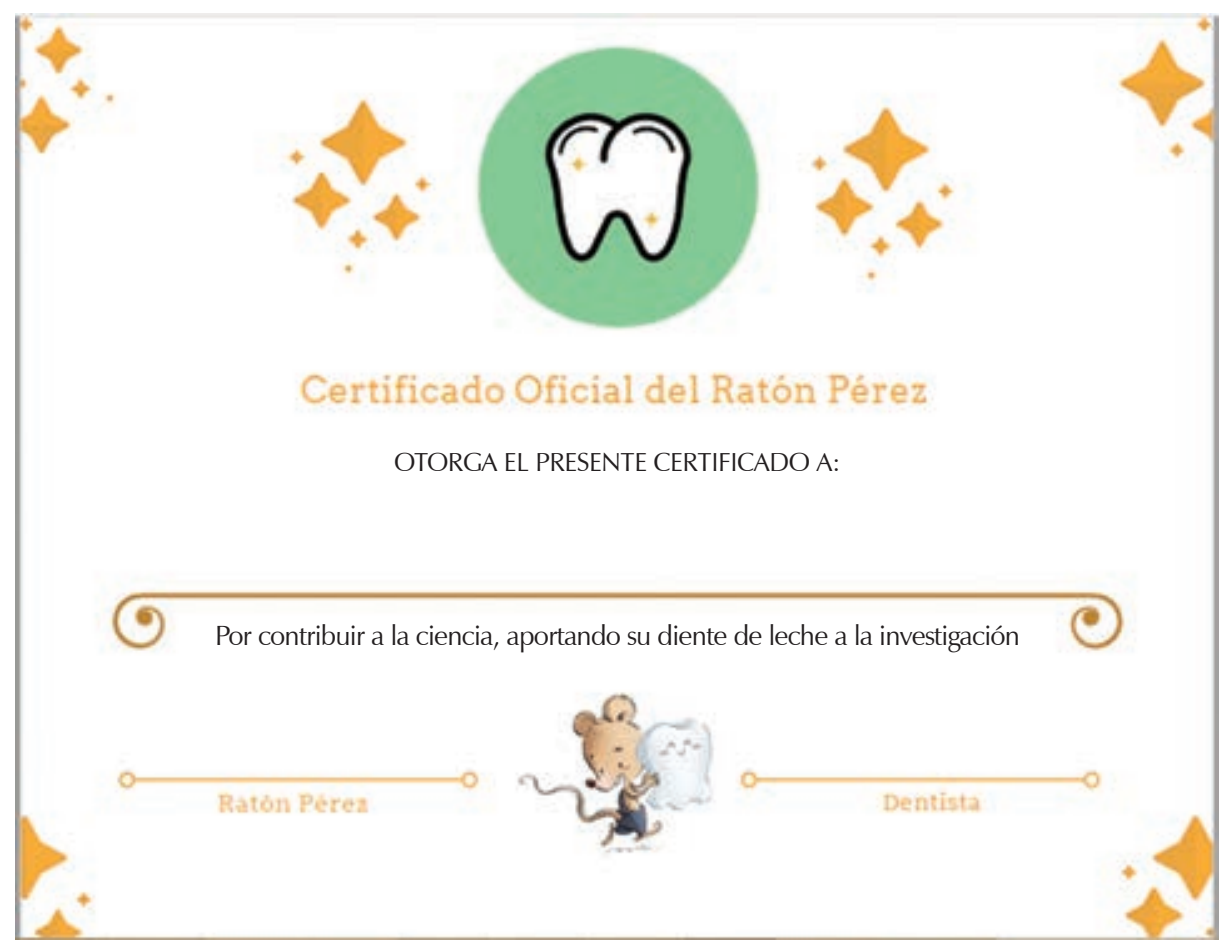

Anexo 3: Formato 2 de certificado para el donante.

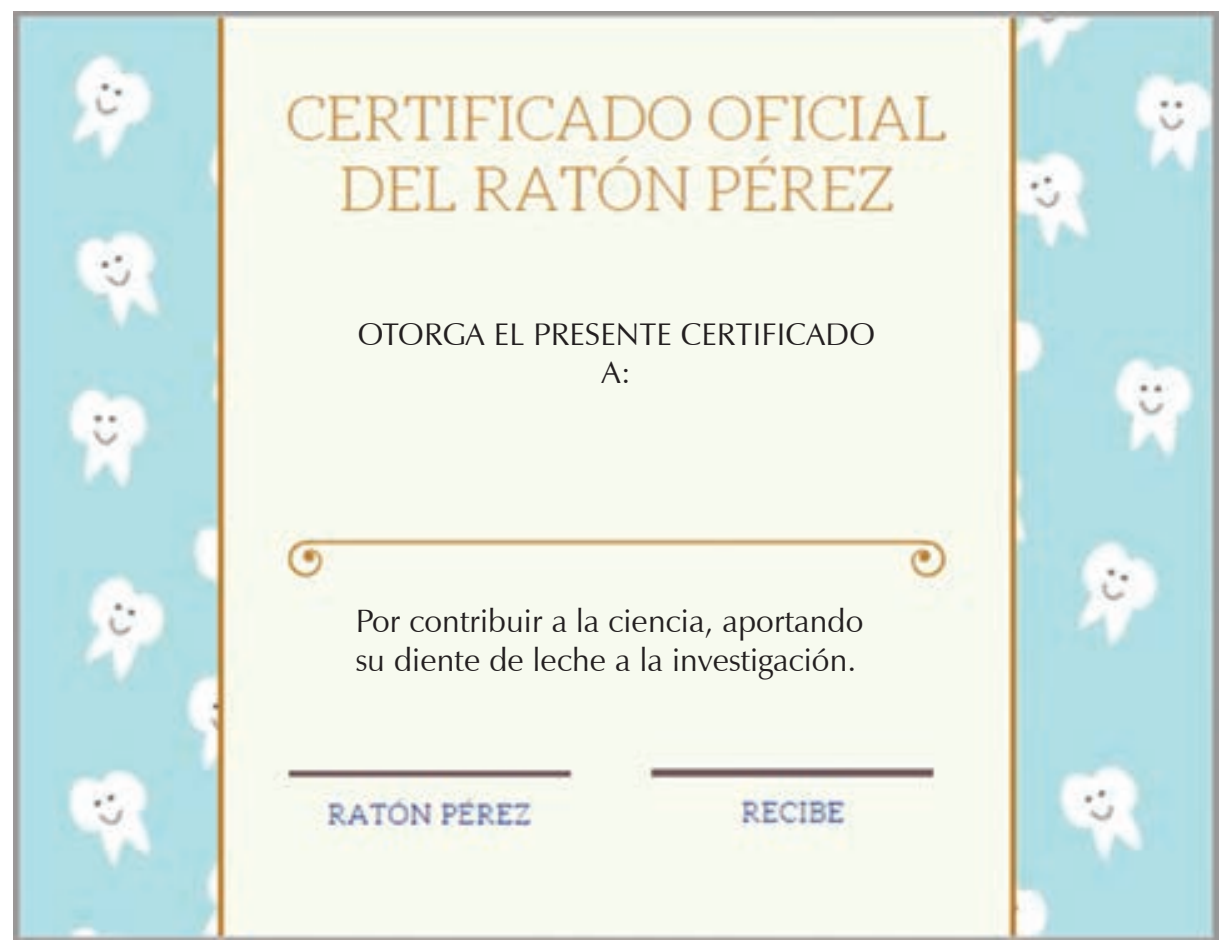


Anexo 4: Instrumentos de medición.

1. Tabla de frecuencia

\begin{tabular}{|l|l|l|l|l|}
\hline Elemento químico & Porcentaje & Dimensiones & Densidad & Frecuencia \\
\hline & & & & \\
\hline & & & & \\
\hline
\end{tabular}

\section{Tabla observacional}

Muestra 1

Observación

Muestra 2

Observación 